\title{
Recovery and characterization of Proteus mirabilis persisters
}

\author{
Rana N. Abokhalil, Walid F. Elkhatib ${ }^{*}$, Mohammad M. Aboulwafa, Nadia A. Hassouna \\ Department of Microbiology and Immunology, Faculty of Pharmacy, Ain Shams University, Cairo 11566, Egypt
}

\begin{abstract}
Bacterial persistence is a phenomenon in which a subpopulation of cells survives antibiotic treatment. The occurrence of bacterial persisters is associated with recurrence of chronic infections. In this study, we aimed to isolate, characterize persister subpopulation in Proteus mirabilis. Persister cells isolation was done by the dosedependent killing of ciprofloxacin. Their characterization was achieved by determining their growth rates. Our results revealed that $1.3 \%$ of persister cells could be recovered from the Proteus mirabilis test isolate. Upon resuscitation, these cell subpopulations exhibited slow growth rate than wild-type cells. As a common phenomenon demonstrated among microbial pathogens, Proteus mirabilis persisters could be isolated with ciprofloxacin. The slow growth rate is one of its characters recorded in the study for persister cells of such bacterial species.
\end{abstract}

Keywords: Persisters; Multidrug tolerance; Proteus mirabilis; Ciprofloxacin; Survival

*Correspondence | Prof. Dr. Walid F. Elkhatib; Department of Microbiology and Immunology, Faculty of Pharmacy, Ain Shams University, African union organization street Abassia, Cairo 11566, Egypt. Email: walid-elkhatib@pharma.asu.edu.eg

Citation | Rana NA, Walid FE, Mohammad MA, Nadia AH. 2018. Recovery and characterization of Proteus mirabilis persisters. Arch Pharm Sci ASU 2(1): 31-36

DOI: 10.21608 /APS.2018.18732

Online ISSN: 2356-8380. Print ISSN: 2356-8399.

Received 12 April 2018. Accepted 17 May 2018.

Copyright: ${ }^{{ }^{2}} 2018$ Abokhalil et al. This is an open-access article licensed under a Creative Commons Attribution 4.0 International License (CC BY 4.0), which permits unrestricted use, distribution, and reproduction in any medium, provided the original author(s) and source are credited Published by: Ain Shams University, Faculty of Pharmacy

\section{INTRODUCTION}

Microbial persistence is the particular capacity of microbes to be able to tolerate immediate contact with lethal ranges of bactericidal antibiotics [1]. In 1944, the first scientist discovered bacterial persistence was Joseph Bigger when he was trying to eliminate Staphylococcus aureus population with penicillin. A small number of cells was found that could stand high lethal antibiotic concentrations [2]. They are dormant, multidrug tolerant, phenotypic variants rather than mutants and have been produced by all microbial pathogens analyzed to date. On removal of the antibiotic stress, they switch back to a growing state, by this means giving rise to a new population that is genetically identical to the wild-type cell $[\mathbf{3 , 4}]$. Their tolerance to antibiotics is mechanistically distinct from resistance $[\mathbf{5 , 6 ]}$. Additionally, the formation of persisters is growth phase-dependent, and their particular number is low inside exponentially growing cultures $(0.0001 \%)$ and this number attains its maximum inside stationary phase which accounts up to $10 \%$ from the whole population [7].

Antibiotics mainly target actively developing cells whereas the drug-tolerant cells are generally dormant. Therefore, this was the first direct 
statement to the mechanism of persistence. The second mechanism, activation of the toxinantitoxin module that can account for the concurrence of two different subpopulations with varying sensitivity to the antibiotic [8]. Transient growth arrest arises in those cells that the toxin concentration rises above the threshold, enabling such cells to persist. Consequently, a transitory growth arrest is the main functional phenomenon associated with persistence [9]. Persisters may be a middle stage in the development of drug resistance owing to their ability to undergo cellular division during persistence. In addition, persisters can accelerate mutagenesis and horizontal gene transfer due to their stressresponse mechanisms [3]. Therefore, persisters may play a role in the development of multidrugresistant bacteria [3]. Eliminating persisters or preventing their emergence should be a substantial target in the treatment of bacterial infections [10]. At the same time, associated problems such as the development of transmissible resistance, toxicity, undesirable side effects should be kept in focus. The aim of the present study was to investigate the formation of persister cells in the pathogen Proteus mirabilis, the possible phenotypic change associated with its formation.

\section{MATERIALS AND METHODS}

\subsection{Microorganism and growth conditions}

A clinical Proteus mirabilis isolates from urine specimen was used in this study. The isolate was identified using their growth characteristics on general, some selective and diagnostic culture media, as well as their biochemical reactions in the classical pathway. The identification was confirmed using API 20E kit (bioMérieux, France). This isolate was cultured in Luria Bertani (LB) medium [11]. For different experiments, a loopful from grown culture on LB agar slant was used to inoculate 5
$\mathrm{mL} \mathrm{LB}$ broth contained in a test tube. The tube was incubated overnight at $37{ }^{\circ} \mathrm{C}$. The culture was centrifuged at $12000 \mathrm{rpm}$ for $5 \mathrm{~min}$ at room temperature and the pellets produced were washed twice with $0.9 \%$ saline and resuspended in saline. To adjust the count of the resultant suspension, the optical density (OD) was adjusted to $600 \mathrm{~nm}$ of 0.1 to get $10^{8} \mathrm{CFU} / \mathrm{mL}$ and in different experiments; the test organism cell suspension was prepared in the same way.

\subsection{MIC determination}

The MIC of ciprofloxacin (Amriya Pharm IND, Alexandria, Egypt) was determined using the agar dilution technique. Experiments were carried out in at least three independent replicates [12].

\subsection{Persistence assay}

Persistence was measured by determining survival upon exposure to ciprofloxacin (Cip) by using dose-dependent killing procedure [13]. In this method, the test isolate was challenged with various concentrations of Cip beginning with 10 fold MIC for $24 \mathrm{~h}$. Proteus mirabilis cell suspension was prepared as described above to be treated with different concentrations of Cip for 24 h at $37{ }^{\circ} \mathrm{C}$ and $200 \mathrm{rpm}$. After treatment, the cells were washed twice with and resuspended in $0.9 \%$ w/v saline. The number of viable persister cells was then quantified by spotting $10 \mu \mathrm{L}$ aliquots of the cell suspension on MacConkey's agar plates. The $\log \mathrm{CFU} / \mathrm{mL}$ values of survivors were plotted against Cip concentrations. A distinct biphasic killing pattern with a plateau of surviving persisters could be obtained. One test concentration of ciprofloxacin within the plateau part of the dose-dependent ciprofloxacin killing curve was selected to be used for recovery of persister cells of the test organism in further experiments [13]. 


\subsection{Persister revival assay}

Persister cells were recovered by exposing the cells suspension of the test organism, prepared as mentioned before to $30 \mu \mathrm{g} / \mathrm{mL}$ ciprofloxacin for $24 \mathrm{~h}$. The cells were collected by centrifugation at $12000 \mathrm{rpm}$ for $5 \mathrm{~min}$ then washed twice with $0.9 \% \mathrm{w} / \mathrm{v}$ saline followed by resuspension in 5 $\mathrm{mL} \mathrm{LB}$ broth. The persister cells were allowed to resuscitate for $6 \mathrm{~h}$ at $37{ }^{\circ} \mathrm{C}$ during which the growth was monitored every hour by measuring the optical density of the cell suspension at 600 nm. As a control, the wild-type cells without ciprofloxacin exposure were similarly treated. The experiment was carried in triplicates and the growth as a function of time was presented graphically [14-16].

\subsection{Statistical analysis}

All values are expressed as means \pm standard deviations (SD). The results of persister cells revival were statistically analyzed using student t-test at 95\% confidence interval using Graph Pad Prism ${ }^{\circledR}$ Version 5.0 (GraphPad Software, La Jolla, CA, USA).

\section{RESULTS}

\subsection{Persister cell isolation}

Ciprofloxacin dose-dependent killing ( $\mathrm{MIC}=$ $0.031 \mu \mathrm{g} / \mathrm{mL}$; sensitive) of Proteus mirabilis test isolate experiment showed a biphasic killing pattern (Fig. 1) The bulk of the population was effectively killed with $0.31 \mu \mathrm{g} / \mathrm{mL}$ ciprofloxacin (10 fold MIC) followed nearly by a plateau with minimal decrease in survival up to $40 \mu \mathrm{g} / \mathrm{mL}$ ciprofloxacin concentration. The percentage of survival at $30 \mu \mathrm{g} / \mathrm{mL}$ ciprofloxacin was recorded to be $1.3 \%$ of the initial cell count and that at 40 $\mu \mathrm{g} / \mathrm{mL}$ ciprofloxacin (1000 fold MIC) was about $1.5 \%$. The survivors along the plateau of ciprofloxacin dose-dependent killing curve could be considered as persisters as they survived the antibiotic treatment. To ensure the persistence, the MIC of these survivors against ciprofloxacin showed no change in its value as compared to the wild-type cell population of the test organism. Additionally, no colonies appeared on the $24 \mathrm{~h}$ at $37{ }^{\circ} \mathrm{C}$ incubated LB agar plates containing 30 $\mu \mathrm{g} / \mathrm{mL}$ ciprofloxacin that were pre-inoculated with survival cells as compared to their growth on LB agar plates alone without added ciprofloxacin.

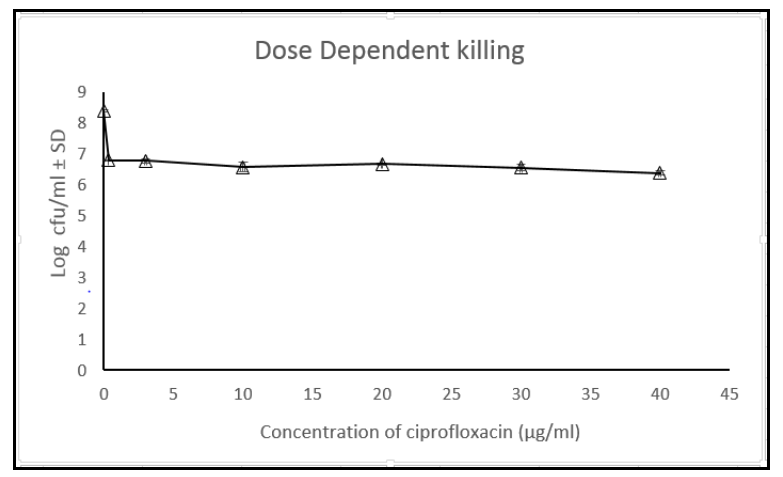

Fig. 1. Ciprofloxacin dose-dependent killing of clinical Proteus mirabilis isolate. The survivors after exposure of the test organism cell suspension to various concentrations of ciprofloxacin was determined after $24 \mathrm{~h}$ contact period and the error bars represent the standard deviation of log-values of the means of three independent experiments were then calculated.

\subsection{Characterization of persister cells}

The persister cells obtained after prolonged treatment with ciprofloxacin $(24 \quad h)$ were characterized by determining their growth profile after regeneration in the nutrient medium. Regeneration in LB show growth profile similar to the normal wild type cells but with a lower rate (Fig. 2). After $5 \mathrm{~h}$ incubation in LB broth under the growth conditions, the persister cells attained an OD approximately equal to $30 \%$ that of the wild-type cells. The results were analyzed using student t-test at $95 \%$ confidence interval giving 
$\mathrm{p}<0.01$ that indicates the significance of the results.

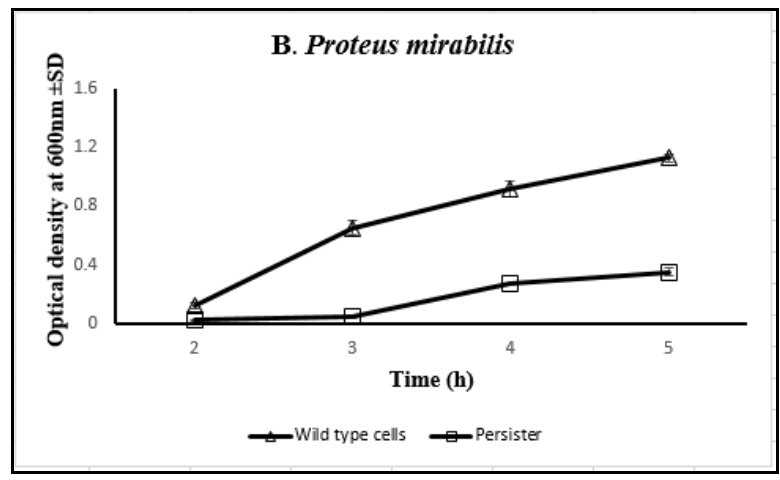

Fig. 2. Growth profile of resuscitated Proteus mirabilis persisters recovered at $30 \mu \mathrm{g} / \mathrm{mL}$ ciprofloxacin in normal saline, $37{ }^{\circ} \mathrm{C}$ and $200 \mathrm{rpm}$ versus untreated control. The OD values represent the means of triplicates \pm SD.

\section{DISCUSSION}

Bacterial persistence is abundant in many bacterial species. Most previous studies have been investigated on Escherichia coli. In this study, the persistence phenomenon was studied in Proteus mirabilis. This organism is mostly known to cause recurrent urinary tract infections that are usually occurred in patients under longterm catheterization. As well as increasing drug resistance to ampicillin, trimethoprim, and ciprofloxacin was reported for Proteus mirabilis [17].

Persistence is the intermediate stage between sensitive wild strain and resistant mutant before resistance being established [18]. Accordingly, if we are capable to inhibit persistence, resistance to antimicrobial agents would decrease and help in ameliorating chronic infections. Persisters represent a small subpopulation of a culture that survives killing with lethal doses of antimicrobial agents [19-21].

Persistence is detected when the bulk of the population is rapidly killed leaving a minor subpopulation persists for a much longer time. In some studies, the authors used $24 \mathrm{~h}$ or $48 \mathrm{~h}$ to isolate it $[\mathbf{2 2 , 2 3 ]}$ while other studies used $3 \mathrm{~h}$ or 4 $\mathrm{h}$ instead [20,24]. The dose-dependent killing curve is characterized by being biphasic, due to the heterogeneous response of the population. When survivor cells are isolated, they allowed to regrow in rich medium and then re-exposed to the same antibiotic treatment. The same heterogeneous response to the drug was observed similar to that in the original population. In accordance with the previous literature, the level of persisters within culture reached approximately $1 \%$ to maximum of $10 \%$ in stationary phase $[25,26]$.

In this study, persisters from Proteus mirabilis upon exposure to ciprofloxacin (1000 fold) MIC for $24 \mathrm{~h}$ represent $1.3 \%$ of the total cell population in the stationary phase. The fluoroquinolone ciprofloxacin is the antibiotic of choice for the treatment of this kind of bacterial infections. In the present study, it represents a worthy example of synthetic drugs against which bacteria have quickly advanced resistance. Additionally, it kills both normal growing cells and slowly growing or non-growing stationaryphase cells, leaving dormant persisters intact. In addition, the dose-dependent killing curve shows biphasic killing.

We hypothesize that tolerance to antibiotics may be due to the shutdown of a target function leaving metabolically inactive dormant cells in which antimicrobial agents could not kill. It looks that in most cases inhibition of the target function is the instantaneous cause of antibiotic tolerance, while the decrease in growth rate is a result of this inhibition. Additional experimentations are needed to know the mechanism of Proteus mirabilis persistence against ciprofloxacin. According to Dörr et al. [27], fluoroquinolones induce persistence in Escherichia coli by preventing ligation reactions of gyrase and topoisomerase resulting in double-strand breaks 
(DSB). Processing of DSBs leads to the induction of the SOS response, the result of which is the production of various repair proteins [27]. This leads to the formation of tolerant persister cells. That is considered an effective bacterial survival strategy for E.coli against ciprofloxacin.

Remarkably, the antibiotic tolerance of persisters is not genetically expressed as progenies of persisters are as susceptible as the parent strains. Consistent with a number of studies, persisters among an isogenic bacterial culture temporarily reside in a slow or nongrowing state and arise both stochastically $[\mathbf{7 , 2 8 -}$ 31]. Researchers proved that upon resuscitation of persister exhibit slow growth rate in comparison with the control [32]. After resuscitation, regrown persisters remain sensitive to ciprofloxacin similar to the wild-type cell. The result noticeably showed that surviving persisters regenerate the original population and are therefore phenotypic variants of the wild type rather than resistant mutants.

\section{CONCLUSION}

Overall, this study was the first to report the persistence phenomenon in Proteus mirabilis. Persisters can be isolated with antibiotic treatment (ciprofloxacin). The slowdown of metabolic functions of subpopulation persister cells was evidenced by the slow growth rate upon resuscitation.

\section{Conflicts of Interest}

The authors declare no conflict of interest.

\section{Acknowledgment}

We would like to thank all staff of Microbiology and Immunology Department, Faculty of Pharmacy, Ain Shams University for the availability of chemicals, other materials and instruments that were used for the accomplishment of this study.

\section{REFERENCES}

1. Dhar N, McKinney JD. Microbial phenotypic heterogeneity and antibiotic tolerance. Curr. Opin. Microbiol. 2007; 10: 30-8.

2. Podlesek Z, Butala M, Šakanović A, Žgur-Bertok D. Antibiotic-induced bacterial lysis provides a reservoir of persisters. Antonie Van Leeuwenhoek. 2016; 109: 5238.

3. Cohen NR, Lobritz MA, Collins JJ. Microbial persistence and the road to drug resistance. Cell Host Microbe. 2013; 13: 632-42.

4. Li B, Qiu Y, Glidle A, Cooper J, Shi H, Yin H. Single cell growth rate and morphological dynamics revealing an "opportunistic" persistence. Analyst. 2014; 139: 3305-13.

5. Gefen $\mathrm{O}$, Balaban NQ. The importance of being persistent: heterogeneity of bacterial populations under antibiotic stress. FEMS Microbiol. Rev. 2009; 33: 70417.

6. Mulcahy LR, Burns JL, Lory S, Lewis K. Emergence of Pseudomonas aeruginosa Strains Producing High Levels of Persister Cells in Patients with Cystic Fibrosis. J. Bacteriol. 2010; 192: 6191-9.

7. Keren I, Kaldalu N, Spoering A, Wang Y, Lewis K. Persister cells and tolerance to antimicrobials. FEMS Microbiol. Lett. 2004; 230: 13-8.

8. Rotem E, Loinger A, Ronin I, Levin-Reisman I, Gabay C, Shoresh $\mathrm{N}$ et al. Regulation of phenotypic variability by a threshold-based mechanism underlies bacterial persistence. Proc. Natl. Acad. Sci. 2010; 107: 12541-6.

9. Balaban NQ, Merrin J, Chait R, Kowalik L, Leibler S. Bacterial persistence as a phenotypic switch. Science. 2004; 305: 1622-5.

10. Wood TK. Strategies for combating persister cell and biofilm infections. Microb. Biotechnol. 2017; 10: 10546.

11. Miller j. h. Experiments in molecular genetics. 1972. 1972.

12. CLSI. Performance Standards for Antimicrobials Susceptibility Testing; Twenty-Fourth Informational Supplement. CLSI Doc. M100-S24 341 Clin. Lab. Stand. Inst. USA ISBN 1-56238-897-5. 2014.

13. Niepa THR, Gilbert JL, Ren D. Controlling Pseudomonas aeruginosa persister cells by weak 
electrochemical currents and synergistic effects with tobramycin. Biomaterials. 2012; 33: 7356-65.

14. Pascoe B, Dams L, S Wilkinson T, Harris L, Bodger O, Mack D et al. Dormant Cells of Staphylococcus aureus Are Resuscitated by Spent Culture Supernatant. PloS One. 2014; 9: e85998.

15. Grassi L, Di Luca M, Maisetta G, Rinaldi AC, Esin S, Trampuz A et al. Generation of Persister Cells of Pseudomonas aeruginosa and Staphylococcus aureus by Chemical Treatment and Evaluation of Their Susceptibility to Membrane-Targeting Agents. Front. Microbiol. 2017. doi:10.3389/fmicb.2017.01917.

16. Kwan BW, Valenta JA, Benedik MJ, Wood TK. Arrested protein synthesis increases persister-like cell formation., Arrested Protein Synthesis Increases Persister-Like Cell Formation. Antimicrob. Agents Chemother. Antimicrob. Agents Chemother. 2013; 57, 57:1468, 1468-73.

17. Kwiecinska-Pirog J, Skowron K, Bartczak W, Gospodarek-Komkowska E. The Ciprofloxacin Impact on Biofilm Formation by Proteus Mirabilis and P. Vulgaris Strains. Jundishapur J. Microbiol. 2016; 9: e32656.

18. Fisher RA, Gollan B, Helaine S. Persistent bacterial infections and persister cells. 464. 2017; 15: 453-64.

19. Singh R, Ray P, Das A, Sharma M. Role of persisters and small-colony variants in antibiotic resistance of planktonic and biofilm-associated Staphylococcus aureus: an in vitro study. J. Med. Microbiol. 2009; 58: 1067-73.

20. Mo"ker N, Dean C, Tao J. Pseudomonas aeruginosa Increases Formation of Multidrug-Tolerant Persister Cells in Response to Quorum-Sensing Signaling Molecules. J of bacteriology. 2010; 192: 1946-1955.

21. Leung V, Lévesque CM. A Stress-Inducible QuorumSensing Peptide Mediates the Formation of Persister Cells with Noninherited Multidrug Tolerance. J. Bacteriol. 2012; 194: 2265-74.

22. Bigger JW. The bactericidal action of penicillin on Staphylococcus pyogenes. Ir. J. Med. Sci. 1926-1967. 1944; 19: 585-95.

23. Hobby GL, Meyer K, Chaffee E. Observations on the Mechanism of Action of Penicillin.*: Soc. Exp. Biol. Med. 2016; 50: 281-5.

24. Goneau LW, Yeoh NS, MacDonald KW, Cadieux PA, Burton JP, Razvi H et al. Selective Target Inactivation Rather than Global Metabolic Dormancy Causes
Antibiotic Tolerance in uropathogens. Antimicrob. Agents Chemother. 2014; 58: 2089-97.

25. Spoering AL, Lewis K. Biofilms and planktonic cells of Pseudomonas aeruginosa have similar resistance to killing by antimicrobials. J. Bacteriol. 2001; 183: 674651.

26. Lewis K. Persister cells and the riddle of biofilm survival. Biochem. Mosc. 2005; 70: 267-74.

27. Dörr T, Vulić M, Lewis K. Ciprofloxacin Causes Persister Formation by Inducing the TisB toxin in Escherichia coli. PLOS Biol. 2010; 8: e1000317.

28. Maisonneuve E, Castro-Camargo M, Gerdes K. (p)ppGpp Controls Bacterial Persistence by Stochastic Induction of Toxin-Antitoxin Activity. Cell. 2013; 154: 1140-50.

29. Prax M, Bertram R. Metabolic aspects of bacterial persisters. Front. Cell. Infect. Microbiol. 2014. doi:10.3389/fcimb.2014.00148.

30. Kaldalu N, Hauryliuk V, Tenson T. Persisters-as elusive as ever. Appl. Microbiol. Biotechnol. 2016; 100: 6545-53.

31. Renbarger TL, Baker JM, Sattley WM. Slow and steady wins the race: an examination of bacterial persistence. Microbiol. 2017 Vol 3 Pages 171-185. 2017. doi:10.3934/microbiol.2017.2.171.

32. Wood TK, Knabel SJ, Kwan BW. Bacterial Persister Cell Formation and Dormancy. Appl. Environ. Microbiol. 2013; 79: 7116-21. 